\title{
mwn.casopoisma.pan.pil PAN \\ Effect of Different Variants of Heat Treatment on Mechanical Properties of the AlSi17CuNiMg Alloy
}

\author{
A. Jarco*, J. Pezda \\ Department of Production Engineering and Automation, University of Bielsko-Biała, \\ ul. Willowa 2, 43- 300 Bielsko-Biała, Poland \\ *Contact for correspondence: e-mail: ajarco@ath.bielsko.pl
}

Received 31.03.2016; accepted in revised form 15.04.2016

\begin{abstract}
Dispersion hardening, as the main heat treatment of silumins having additions of copper and magnesium, results in considerable increase of tensile strength and hardness, with simultaneous decrease of ductility of the alloy. In the paper is presented an attempt of introduction of heat treatment operation consisting in homogenizing treatment prior operation of the dispersion hardening, to minimize negative effects of the T6 heat treatment on plastic properties of hypereutectoidal AlSi17CuNiMg alloy. Tests of the mechanical properties were performed on a test pieces poured in standardized metal moulds. Parameters of different variants of the heat treatment, i.e. temperature and time of soaking for individual operations were selected basing on the ATD (Thermal Derivation Analysis) diagram and analysis of literature. The homogenizing treatment significantly improves ductility of the alloy, resulting in a threefold increase of the elongation and more than fourfold increase of the impact strength in comparison with initial state of the alloy. Moreover, the hardness and the tensile strength $\left(\mathrm{R}_{\mathrm{m}}\right)$ of the alloy decrease considerably. On the other hand, combination of the homogenizing and dispersion hardening enables increase of elongation with about $40 \%$, and increase of the impact strength with about $25 \%$, comparing with these values after the T6 treatment, maintaining high hardness and slight increase of the tensile strength, comparing with the alloy after the dispersion hardening.
\end{abstract}

Keywords: Heat treatment, Homogenizing, Aluminum alloys, Mechanical properties, Elongation

\section{Introduction}

Growing tendency of aluminum alloy castings has practically reached level of $20 \%$ of total mass of worldwide production of the castings, basing on statistics from the year 2014 [1], what fully justifies research projects connected with extension of implementation of such castings and better use of their properties.

Aluminum alloys from the $\mathrm{Al}-\mathrm{Si}$ group are used to production of the castings; such alloys find broad applications in production of machinery parts and in automotive industry. Hypereutectoid alloys of the AlSi17 type are mainly used to production of heavy duty pistons and components of cylinder heads to combustion engines [2]. These alloys are mainly characteristic of good mechanical properties, low specific weight and relatively low elongation $[3,4,5]$. By properly selected thermal treatment of such alloys in liquid state, as well as in solid state, it is possible to have effect on morphology of precipitations of primary and eutectic silicon [2].

Standard heat treatment of the silumins, comprising copper and magnesium additions, is precipitation hardening, consisting of two operations: solutioning and artificial or natural ageing [6], what enables much better mechanical properties of the castings with simultaneous decrease of the elongation and ductility $[7,8,9]$.

Having as the objective minimization of detrimental effects of the dispersion hardening on ductility of the alloy, the T6 heat 
treatment was preceded by the homogenizing operation, performed prior the solutioning treatment and aimed at reduction of differences in concentration of chemical elements in crystals, what can be achieved through diffusion changes occurring at high temperatures and during long times of the soaking [10,11].

\section{Methodology of the research}

The investigations were performed for the hypereutectoid AlSi17CuNiMg alloy. The alloy was heat treated by homogenizing operation, dispersion hardening and variants of the heat treatment consisting of these two operations. Chemical composition of the investigated alloy is specified in the Table 1.

Table 1.

Chemical composition of the AlSi17CuNiMg alloy

\begin{tabular}{ccccc}
\hline \multicolumn{5}{c}{ Chemical composition $/$ mass \% } \\
\hline $\mathrm{Si}$ & $\mathrm{Cu}$ & $\mathrm{Zn}$ & $\mathrm{Fe}$ & $\mathrm{Mg}$ \\
\hline 16,2 & 1,35 & 0,03 & 0,35 & 0,75 \\
\hline $\mathrm{Ni}$ & $\mathrm{Mn}$ & $\mathrm{Pb}$ & $\mathrm{Ti}$ & $\mathrm{Al}$ \\
\hline 1,0 & 0,20 & 0,03 & 0,05 & rest \\
\hline
\end{tabular}

The test pieces for tests of the mechanical properties were poured in standardized metal moulds ( $\mathrm{PN}-88 / \mathrm{H}-88002$ standard), and prior pouring into the mould heated to temperature $250^{\circ} \mathrm{C}$. Temperature of the alloy in crucible during the pouring amounted to $720^{\circ} \mathrm{C}$. The test pieces were divided into five groups resulting from predetermined number of the heat treatment variants of the investigated alloy:

1. Initial alloy - without treatment $(\mathrm{F})$,

2. Homogenizing (cooling with furnace - O3p),

3. Dispersion hardening (T6),

4. Homogenizing (cooling with furnace) and dispersion hardening $(\mathrm{O} 3 \mathrm{p}+\mathrm{T} 6)$

5. Homogenizing (cooling in the air) and dispersion hardening $(\mathrm{O} 3 \mathrm{a}+\mathrm{T} 6)$

In the next step, it has been performed the heat treatment and the tests of mechanical properties of the alloy.

Temperature of the test pieces in course of the heating and soaking was controlled continuously by measurement of air temperature inside chamber of the furnace, and temperature of the control specimen, maintaining it within limits $\pm 5^{\circ} \mathrm{C}$ from the preset value.

Diagram of course of the melting and crystallization process (the ATD diagram) was used to determination of temperature of the homogenizing treatment (Fig.1). Temperature of the homogenizing treatment was assumed as $t_{u}=515^{\circ} \mathrm{C}$ (point $\mathrm{A}$ ), while time of the soaking $\tau_{\mathrm{u}}=10 \mathrm{~h}$ was selected on the basis of the literature $[4,10,12]$. The test pieces after the homogenizing were cooled together with the furnace (p) or in the air (a).

Temperature of the solutioning $\mathrm{t}_{\mathrm{p}}=485^{\circ} \mathrm{C}$ (Fig. 1. - point $\mathrm{B}$ ) and the ageing $t_{s}=180^{\circ} \mathrm{C}$ (Fig. 1. - Point $\mathrm{C}$ ) were also taken on the basis of the ATD diagram. Time of operations of the solutioning $\left(\tau_{\mathrm{p}}=2 \mathrm{~h}\right)$ and the ageing $\left(\tau_{\mathrm{s}}=3,5 \mathrm{~h}\right)$ was selected with objective of production of as high as possible tensile strength $\left(\mathrm{R}_{\mathrm{m}}\right)$ and the hardness. After the solutioning treatment the test pieces were cooled in water at temperature $20^{\circ} \mathrm{C}$, and next artificially aged.

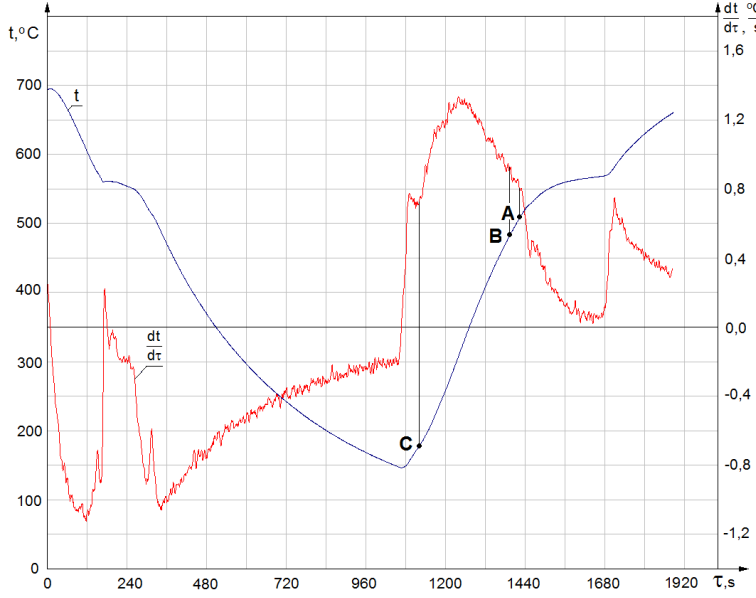

Fig. 1. ATD diagram of the AlSi17CuNiMg alloy

To determine effects of the heat treatment of the initial alloy, and the alloy after different variants of the heat treatment, it has been performed tests of the mechanical properties (tensile strength $\left(\mathrm{R}_{\mathrm{m}}\right)$ and elongation $\left(\mathrm{A}_{5}\right)$ ) on fivefold test pieces with diameter $\phi 10 \mathrm{~mm}$, produced according with the PN-EN ISO 6892-1:2010P standard [13]. The Brinell hardness was measured with use of Brinell method on the hardness tester of the PRL 82 type (steel ball with diameter $\phi 10 \mathrm{~mm}$, under load of $9800 \mathrm{~N}$ for 30 seconds). Measurement of the impact strength was performed basing on the simplified method [14], on the Charpy pendulum machine of the VEB 50J type, using cylindrical test pieces with notch.

\section{Description of obtained results}

List of obtained values of the mechanical properties of the investigated alloy in its initial state and after different variants of the heat treatment is presented in the Table 2.

Table 2.

Mechanical properties of the AlSi17CuNiMg alloy

\begin{tabular}{|c|c|c|c|c|c|}
\hline \multirow[t]{2}{*}{ Lp. } & \multirow{2}{*}{$\begin{array}{c}\text { Type of heat } \\
\text { treatment } \\
\text { used }\end{array}$} & $\mathrm{R}_{\mathrm{m}}$ & $\mathrm{A}_{5}$ & Hardness & $\begin{array}{l}\text { Impact } \\
\text { strength } \\
\text { KC }\end{array}$ \\
\hline & & $\mathrm{MPa}$ & $\%$ & HB & $\mathrm{kJ} / \mathrm{cm}^{2}$ \\
\hline 1 & $\mathrm{~F}$ & 208 & 2,2 & 91 & 32 \\
\hline 2 & O3p & 177 & 6,5 & 63 & 138 \\
\hline 3 & T6 & 328 & 1,3 & 129 & 39 \\
\hline 4 & $\mathrm{O} 3 \mathrm{p}+\mathrm{T} 6$ & 346 & 1,8 & 129 & 48 \\
\hline 5 & $\mathrm{O} 3 \mathrm{a}+\mathrm{T} 6$ & 344 & 1,9 & 126 & 49 \\
\hline
\end{tabular}

The diagrams recorded during the static tensile tests, performed for the initial alloy and after successive variants of the heat treatment are shown in the Fig. 2. Making comparison of these curves it is possible to estimate how the elongation, the tensile strength $\left(\mathrm{R}_{\mathrm{m}}\right)$ and the Young's modulus [15] are changing after the homogenizing treatment, after dispersion hardening treatment, as well as after connection of these operations. 


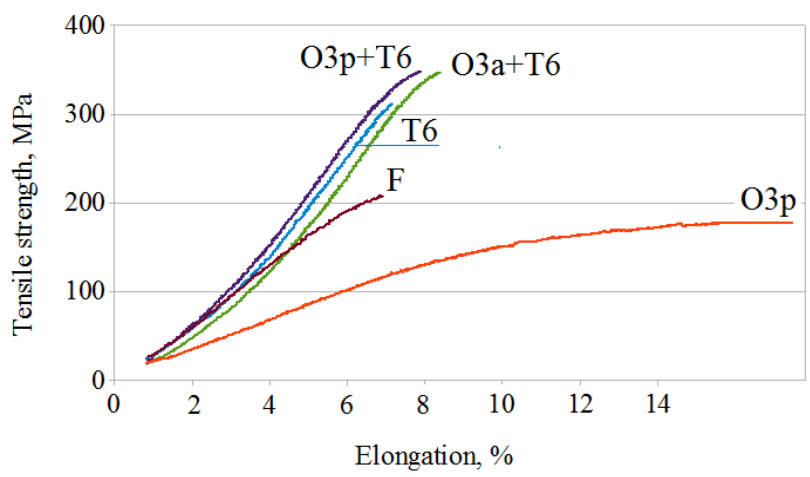

Performed different variants of the heat treatment resulted in change of microstructure of the investigated alloy (Fig. 3).

Fig. 2. Stress-strain diagrams of the test pieces
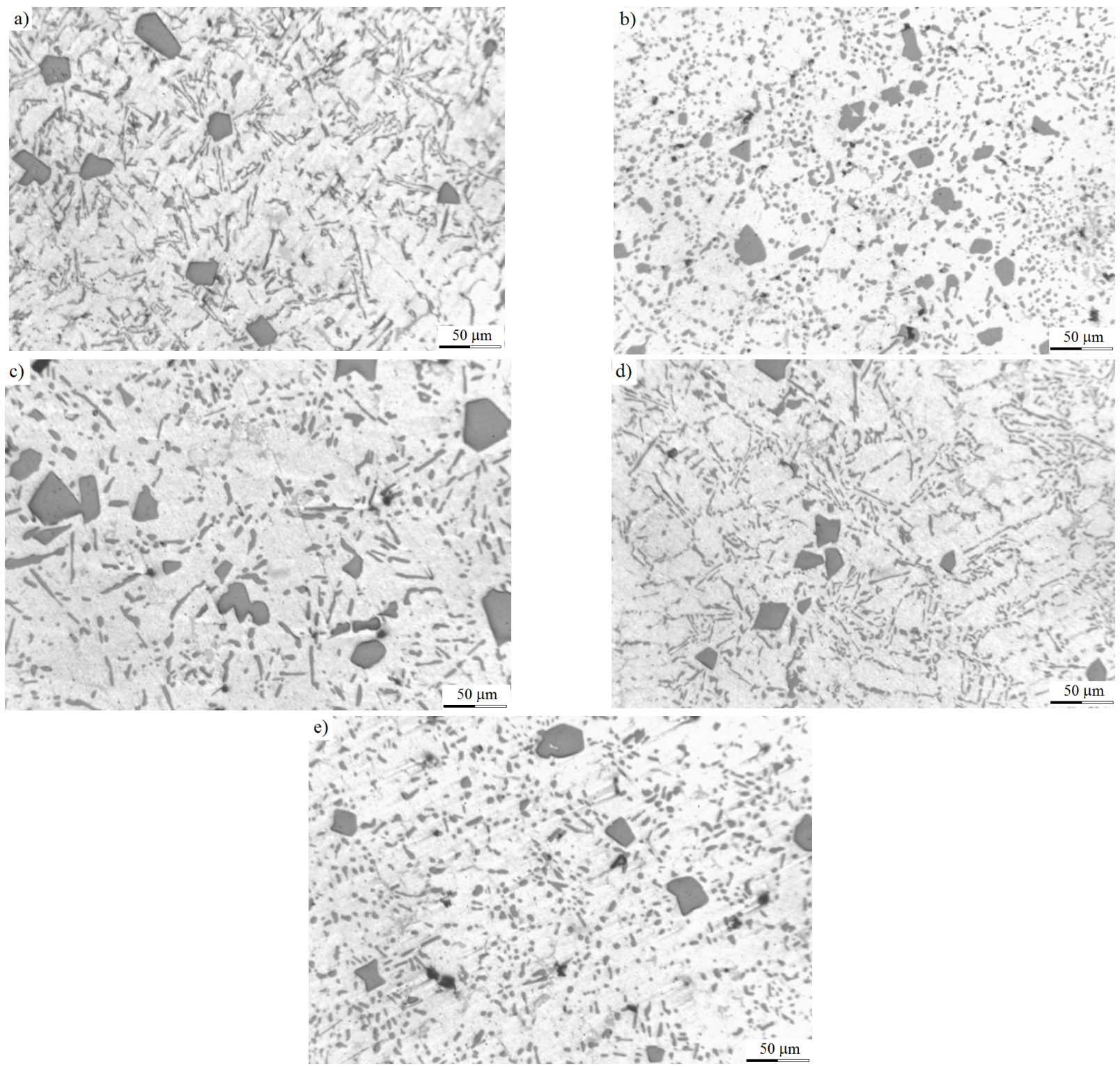

Fig. 3. Microstructures of the AlSil7CuNiMg alloy, a) initial alloy F, b) O3p, c) T6, d) O3p+T6, e) O3a+T6 
The Figure $3 \mathrm{a}$ presents microstructure of the initial alloy, where on background of the phase $\alpha$ are seen big precipitations of the primary silicon with irregular and sharp boundaries, and notmodified lamellar precipitations of eutectic silicon. After homogenizing treatment the shape of the eutectic silicon (Fig. 3b) is sharply refined and rounded. Also boundaries of precipitations of the primary silicone have undergone a partial rounding. Dispersion hardening (Fig. 3c) resulted in a slight changes of morphology of precipitations of the eutectic silicon, comparing with the initial alloy. After connection of the dispersion hardening and the homogenizing operation (Fig. $3 \mathrm{~d}$ and $3 \mathrm{e}$ ) it have been obtained a microstructures with small, spheroidal precipitations of the eutectic silicone, without any significant change of shape of the hypereutectoid silicon.

Refining and spheroidization of the eutectic silicon precipitations obtained after homogenizing and combined treatment, consisting in connection of the homogenizing and dispersion hardening, have allowed to obtain a higher values of elongation and hardness of the alloy with maintained high tensile strength $\left(\mathrm{R}_{\mathrm{m}}\right)$.

\section{Conclusions}

The homogenizing treatment results in significant increase of the ductility. The elongation $\left(\mathrm{A}_{5}\right)$ can be increased threefold, while the impact strength (KC) can be increased fourfold, comparing with the alloy without the heat treatment, with simultaneous decrease of the $\left(\mathrm{R}_{\mathrm{m}}\right)$ strength with $15 \%$ and the hardness (HB) with 30\%.

Implementation of the dispersion hardening enables obtainment of the alloy with increased tensile strength $\left(\mathrm{R}_{\mathrm{m}}\right)$ (increase with about 60\%) and with increased hardness (increase with about $40 \%$ ), with simultaneous significant decrease of the $\mathrm{A}_{5}$ $(40 \%)$ with respect to the initial alloy.

Combination of the dispersion hardening of the silumins with the homogenizing treatment enables production of the alloy characteristic of nearly $40 \%$ higher unit elongation and $25 \%$ increase of the impact strength, in relation to the alloy after dispersion hardening only. Simultaneously, its tensile strength slightly increases, while the hardness is maintained on a high level, comparing with the alloy after the T6 heat treatment.

Cooling method of the material after the homogenizing, i.e. together with the furnace or in the air, in connection with the T6 treatment, does not have any effect on change of the mechanical properties of the AlSi17CuNiMg alloy.

Selection of a proper variant of the heat treatment allows obtaining the castings with differentiated mechanical properties, depending on an application and a requirements concerning usage of components.

\section{References}

[1] Sobczak, J.J., Balcer, E. \& Kryczek, A. (2015). Polish foundry against the background of the global foundry, current state and trends. In Konferencja techniczno szkoleniowa "Oszczędność energii i materiałów w produkcji innowacyjnych odlewów", 11 December 2015, Kraków, Poland. (in Polish).

[2] Piątkowski, J. \& Matuła, T. (2015). The microstructure and mechanical properties of the AlSi17Cu5 alloy after heat treatment. Archives of Metallurgy and Materials. 60(3), 1813-1817.

[3] Górny, Z. (1992). Casting non-ferrous alloys. Warszawa: WNT. (in Polish).

[4] Dobrzański, L.A. (2006). Engineering materials and materials design. Warszawa: WNT. (in Polish)

[5] Zolotorevsky, V.S., Belov, N.A. \& Glazoff, M.V. (2007). Casting Aluminium Alloys. Oxford: Elsevier.

[6] Mohamed, A.M.A. \& Samuel, F.H. (2012). A review on the heat treatment of $\mathrm{Al}-\mathrm{Si}-\mathrm{Cu} / \mathrm{Mg}$ casting alloys. Czerwinski $\mathrm{F}$. (Eds.). Heat Treatment - Conventional and Novel Applications. 55-72. InTech.

[7] Pezda, J. (2010). Effect of heat treatment operations on the $\mathrm{R}_{\mathrm{m}}$ tensile strength of silumins. Archives of Foundry Engineering. 10(4), 61-64.

[8] Piątkowski, J. (2001). Influence of the heat treatment on the mechanical properties of the AlSi17 alloy. Archives of Foundry. 1(2), 557-564. (in Polish)

[9] Sjölander, E. \& Seifeddine, S. (2010). The heat treatment of $\mathrm{Al}-\mathrm{Si}-\mathrm{Cu}-\mathrm{Mg}$ casting alloys. Journal of Materials Processing Technology. 210, 1249-1259.

[10] Domke, W. (1989). Vademecum of materials. Warszawa: WNT. (in Polish)

[11] Jarco, A. \& Pezda, J. (2015). Impact of various types of heat treatment on mechanical properties of the EN AC-AlSi6Cu4 alloy. Archives of Foundry Engineering. 15(2), 35-38.

[12] Jabłoński, S. (1971). Heat treater small guide-book. Warszawa: WNT. (in Polish)

[13] PN-EN ISO 6892-1:2010P. Metals - Tensile test - Part1 Test method in ambient temperature. Polish Committee for Standardization. (in Polish).

[14] Poniewierski, Z. (1989). Crystallization, structure and properties of silumins. Warszawa: WNT. (in Polish).

[15] Niezgodziński, M.E. \& Niezgodziński, T. (2010). Strength of materials. Warszawa: WNT. (in Polish). 